\title{
On the microstructure and interfacial properties of sputtered nickel thin film on Si $\left(\begin{array}{lll}1 & 0 & 0\end{array}\right)$
}

\author{
B GEETHA PRIYADARSHINI ${ }^{\mathrm{a}, *}$, S AICH ${ }^{\mathrm{b}}$ and M CHAKRABORTY \\ ${ }^{a}$ Materials Science Division, PSG Institute of Advanced Studies, Peelamedu, Coimbatore 641 004, India \\ ${ }^{\mathrm{b}}$ Department of Metallurgical and Materials Engineering, Indian Institute of Technology, Kharagpur 721 302, India
}

MS received 25 November 2013; revised 9 January 2014

\begin{abstract}
Ni films of thickness ranging from 150 to $250 \mathrm{~nm}$ were deposited by DC magnetron sputtering on to Si (100) substrates maintained at room temperature and followed by post-annealing at 300 and $500{ }^{\circ} \mathrm{C}$ for $30 \mathrm{~min}$. Other set of $\mathrm{Ni}$ films were deposited on to $\mathrm{Si}\left(\begin{array}{lll}1 & 0 & 0\end{array}\right)$ substrates held at annealing temperature of 300 and $500{ }^{\circ} \mathrm{C}$ for $30 \mathrm{~min}$. Microstructural investigation by field emission scanning electron microscope (FE-SEM) and atomic force microscope (AFM) revealed columnar morphology with voided boundaries for films deposited at room temperature and was retained after post-deposition annealing at higher temperatures. Nickel silicide formation with isosceles triangle diffusion front was confirmed by cross-sectional highresolution transmission electron microscopy (X-HRTEM) for post-annealed Ni films. Thin film deposited at high substrate temperatures having near-equiaxed structure found to be the best route to fabricate thin films without silicide formation.
\end{abstract}

Keywords. Sputtering; thin film; diffusion; morphology.

\section{Introduction}

Thin film shape memory microactuators are gaining technological interest in micro-electro-mechanical systems (MEMs) due to the intrinsic property of one-way shape memory effect (Kohl 2004). One such material of interest is Ti-Ni alloy thin film, which is nowadays being incorporated as MEMS-based microactuators and transducers (Walker et al 1990; Johnson 1991; Fu et al 2004). For a Ti-Ni thin film to work as micro-device, control over working temperature and compositional tuning during deposition are the prime requisites. Due to inflexibility in composition adjustment, the fabrication of the Ti-Ni thin film by sputter deposition with Ti-Ni alloy target continues to be a challenge. Several works were carried out to combat the composition inflexibility either by cosputtering Ti-Ni alloy target with Ti targets (Takabayashi et al 1997; Shih et al 2001; Fu et al 2003) or by incorporating the Ti plates which required a number of adjustments for size, shape, geometry, number and position of the plates (Wolf and Heuer 1995; Ishida et al 1999; Chu et al 2000; Surbled et al 2001). Further, works were developed by separately sputtering elemental targets of $\mathrm{Ni}$ and $\mathrm{Ti}$ and adjusting the individual powers (Krulevitch et al 1996; Ohta et al 2000; Sanjabi et al 2005). This method of sputtering was remarkably flexible and simple

*Author for correspondence (geethapriyadarshini@gmail.com) to control the composition of the resulting $\mathrm{Ti}-\mathrm{Ni}$ thin film.

$\mathrm{Ni}-\mathrm{Ti}$ shape memory alloy films sputter deposited on $\mathrm{Si}$ substrates are predominantly amorphous when deposited at room temperature, and annealing at temperatures above $500{ }^{\circ} \mathrm{C}$ is necessary to crystallize the films. Crystallization of $\mathrm{Ti}-\mathrm{Ni}$ films by in situ heating during deposition and post-deposition annealing of the films often lead to the formation of reaction products at the interface (Stemmer et al 1997; Chen and Wu 2000; Wu et al 2001; Qiu et al 2003). These metal silicides were reported to have an adverse effect on the shape memory behaviour which in turn influenced the performance of microactuators (Wu et al 2004). Ni is the primary diffusing species among $\mathrm{Ti}$ and $\mathrm{Si}$. During annealing, silicide reaction is initiated between the $\mathrm{Ni}-\mathrm{Ti}$ and $\mathrm{Si}$ interface (Wu et al 2001). Further, they observed reaction products such as $\mathrm{NiSi}_{2}$ and TiNiSi being formed with increase in the annealing temperature. Recently, Martins et al (2008) reported the formation of interfacial diffusion layers of $\mathrm{NiSi}_{2}$ and $\mathrm{Ti}_{4} \mathrm{Ni}_{4} \mathrm{Si}_{7}$ that render high residual stress and low recovery stress in $\mathrm{Ni}-\mathrm{Ti}$ shape memory alloy thin film.

Atomic diffusion and interface reaction can be controlled by appropriate choice of reacting components, reaction paths and products. There are reports on restricting the interfacial reactions in $\mathrm{Ni}-\mathrm{Ti} / \mathrm{Si}$ interfaces during crystallization process by depositing thin layer of SiN by PECVD on Si substrate (Wu et al 2004; Fu et al 2005). 
Out of $\mathrm{Ni}$ and $\mathrm{Ti}$ elemental targets, $\mathrm{Ni}$ was chosen in the present study since they are primary diffusing species at lower temperatures and their existence needs to be understood. Metal motion is dominant in the formation of silicides with the diffusion coefficient for $\mathrm{Ni}$ atoms being greater than the coefficients for Si atoms (D'Heurle et al 1984; Julies et al 1999). In Ni/Si system, the formation of nickel silicides is a sequential growth of three phases, namely $\mathrm{Ni}_{2} \mathrm{Si}, \mathrm{NiSi}$ and $\mathrm{NiSi}_{2}$. This is based upon the temperature of formation (Poate et al 1978). The driving force for the silicide formation is decrease in free energy and the external energy input accelerating the silicide formation by changing the thermodynamic energy of the system. Nickel disilicides $\left(\mathrm{NiSi}_{2}\right)$ are being largely employed as metal-oxide-semiconductor field-effect transistors (MOSFETs) which form at about $800{ }^{\circ} \mathrm{C}$ and

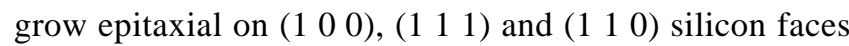
(Abhaya et al 2007). It is important to point out here that, though there are reports on formation of nickel silicides at temperatures as low as $200{ }^{\circ} \mathrm{C}$, in the present study we prefer to investigate $\mathrm{Ni}-\mathrm{Si}$ interactions at $300{ }^{\circ} \mathrm{C}$. The reason being that as-deposited amorphous $\mathrm{Ni}-\mathrm{Ti}$ thin film begins to crystallize only at temperatures greater than $300{ }^{\circ} \mathrm{C}$.

The authors believe that the present study on the interfacial reactions $\mathrm{Ni} / \mathrm{Si}$ is significant with respect to shape memory behaviour of near equiatomic Ni-Ti thin film which is highly sensitive to compositional change. In this context, Ni layers of different thicknesses, when introduced as interlayer, were found to restrict the diffusion of $\mathrm{Cu}$ into Si (Abdul-Letif 2007) and $\mathrm{Au}$ into $\mathrm{Cu}$ promoting good adhesion and excellent diffusion barrier (Chang 1986).

The work reported here is an effortless method to minimize the interfacial reactions in $\mathrm{Ni}-\mathrm{Ti} / \mathrm{Si}$ by introducing Ni layer as a diffusion barrier instead of incorporating SiN and TiN layers. This study is considered to be the basis for further investigation on the interfacial reactions in $\mathrm{Ni}-\mathrm{Ti} / \mathrm{Ni} / \mathrm{Si}$ thin film which can eventually lead to reproducible and reliable shape memory effect.

\section{Materials and method}

A schematic diagram of the RF and DC magnetron sputtering system with sputter-down assembly employed to deposit Ni films is shown in figure 1(a). The sputtering targets are $60^{\circ}$ inclined to each other in confocal geometry located on the top of the chamber facing the substrate platform (figure 1b). Ni films of thickness varying from 150 to $250 \mathrm{~nm}$ were deposited from pure 3 inch Ni target (99.99\%) onto $1^{\prime \prime} \times 1^{\prime \prime}$ Si (1 00 ) substrate by DC magnetron sputtering method. Prior to the depositions, Si substrates were ultrasonically cleaned with acetone and alcohol to remove the surface contaminants. Thereafter, Si substrates were etched in hydrofluoric acid in order to remove the surface oxide. After being dried, they were loaded into the vacuum chamber immediately. The target-substrate distance was fixed at $150 \mathrm{~mm}$ for all the depositions. Substrates were rotated at a speed of $26 \mathrm{rpm}$ in order to maintain the uniformity in the resulting films. Ar gas with a constant flow of $50 \mathrm{sccm}$ was used as the sputtering gas. The chamber was pumped down to $2 \times 10^{-6}$ Torr by turbo molecular pump and Ar gas was backfilled. Sputtering gas pressure of 20 mTorr was maintained during the deposition. The deposition conditions of $\mathrm{Ni}$ films are shown in table 1 . The substrate temperature was maintained at room temperature, 300 and $500{ }^{\circ} \mathrm{C}$. The room temperature deposited films further were annealed at 300 and $500{ }^{\circ} \mathrm{C}$ for $30 \mathrm{~min}$ in vacuum. Annealing was carried out after the deposition without breaking the vacuum (under base pressure of $2 \times 10^{-6}$ Torr) to rule out the possibility of oxidation in $\mathrm{Ni}$ films at higher temperatures.
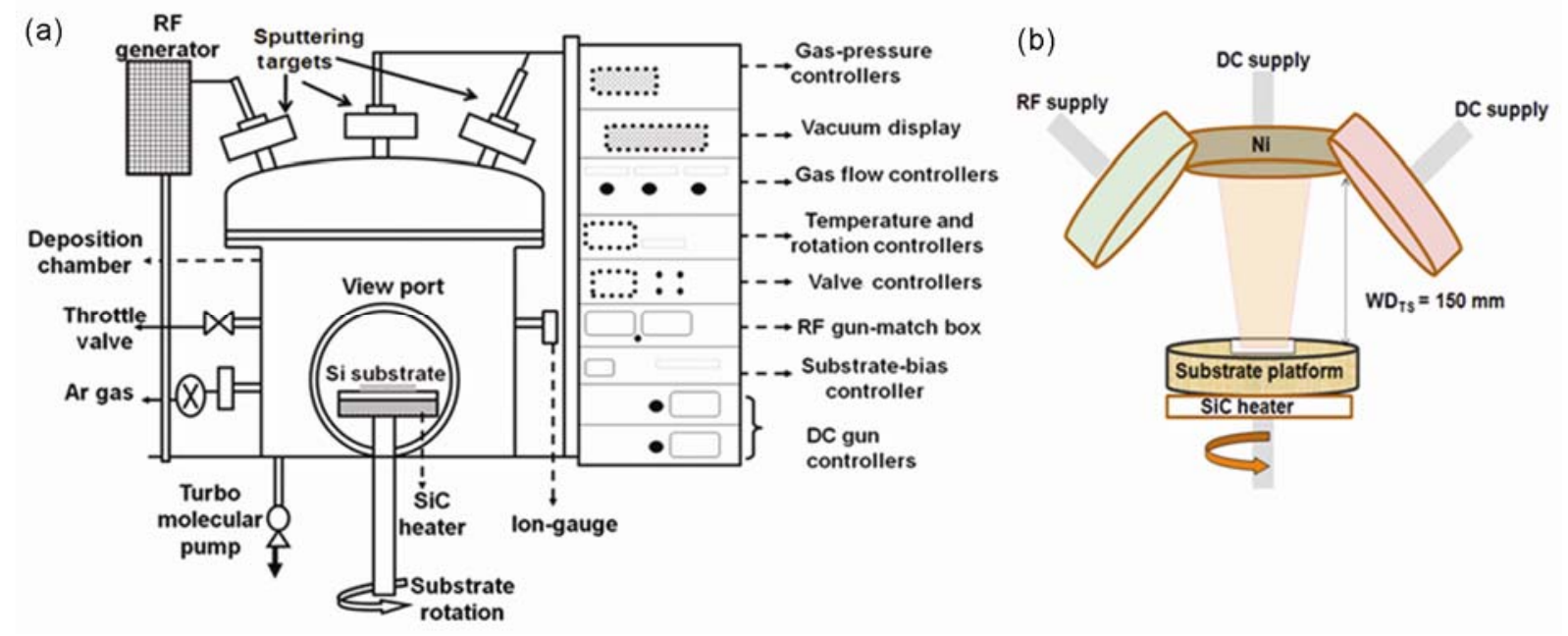

Figure 1. Schematic diagram of (a) RF-DC magnetron sputtering system and (b) location of target, substrate, and heater. 
Table 1. Experimental conditions adopted for Ni to study the influence of in situ substrate temperature and post-annealing temperature.

\begin{tabular}{lccccccc}
\hline $\begin{array}{l}\text { Argon gas } \\
\text { pressure (mTorr) }\end{array}$ & $\begin{array}{c}\text { STD } \\
(\mathrm{mm})\end{array}$ & $\begin{array}{c}\text { DC } \\
\text { power }(\mathrm{W})\end{array}$ & $\begin{array}{c}\text { In situ substrate } \\
\text { temperature }\left({ }^{\circ} \mathrm{C}\right)\end{array}$ & $\begin{array}{c}\text { Post-annealing } \\
\text { temperature }\left({ }^{\circ} \mathrm{C}\right)\end{array}$ & $\begin{array}{c}\text { Annealing } \\
\text { time }(\mathrm{min})\end{array}$ & $\begin{array}{c}\text { Deposition } \\
\text { time }(\mathrm{min})\end{array}$ & $\begin{array}{c}\text { Deposition rate } \\
( \pm 3 \mathrm{~nm} / \mathrm{min})\end{array}$ \\
\hline 20 & 150 & 300 & 27 & - & - & 10 & 17 \\
20 & 150 & 300 & 27 & 300 & 30 & 10 & 17 \\
20 & 150 & 300 & 27 & 500 & - & 30 & 17 \\
20 & 150 & 300 & 300 & - & - & 30 & 13 \\
20 & 150 & 300 & 500 & - & & \\
\hline
\end{tabular}

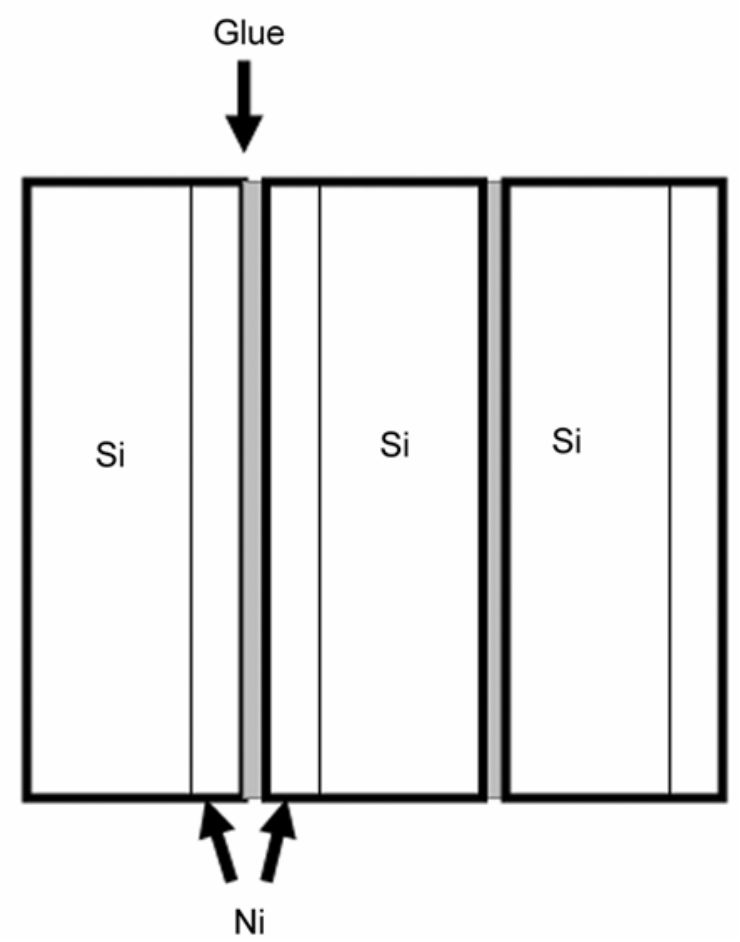

Figure 2. Cross-sectional TEM sample preparation.

The film thickness was measured using step height on a masked silicon substrate by surface profiler (VeecoDektak 150). Grazing incidence X-ray diffraction (GIXRDPhilips X'Pert) was employed to determine crystalline phases generated. The grazing incidence angle is fixed to $0.5^{\circ}$ for scan range $(2 \theta) 30-100^{\circ}$. The surface studies were observed by atomic force microscopy (AFM) (Veeco-Nanoscope IV) under tapping mode. The microstructural studies were carried out on planar and crosssectional films by field emission scanning electron microscope (Carl Zeiss-SUPRA40).

JEOL-JEM 2100 high-resolution transmission electron microscope (HR-TEM) was employed to characterize planar and cross-sectional Ni samples for microstructure. Cross-section TEM samples were prepared for the detailed structural analysis at the interface. The sample was cut into 6 pieces of size $5 \times 4 \mathrm{~mm}^{2}$ using Gatan model 150 ultra-sonic disc cutter. Film to film and Si to
Si sides were sandwiched together with an adhesive. The schematic of one such block (film to film and $\mathrm{Si}$ to $\mathrm{Si}$ ) is represented in figure 2 . The sample was then glued to the hollow stainless-steel tube in order to further reduce the diameter to $2.3 \mathrm{~mm}$ by using ultrasonic disc cutter. The cylindrical sample with dimension $5 \times 2 \cdot 3 \mathrm{~mm}^{2}$ was fitted into brass tube and cut into pieces using Isomet cutter 1000. After cutting, the samples were carefully polished in rotopol grinder fitted with fine emery paper to reduce the thickness to $<100 \mu \mathrm{m}$. Finally, the samples were thinned by ion milling for $2 \mathrm{~h}$ with ion beam energy of $4.8 \mathrm{keV}$.

\section{Results and discussion}

\subsection{Grazing incidence X-ray diffraction analysis}

Figure 3 shows the GIXRD pattern for Ni films deposited at room temperature and followed by post-annealing at temperatures 300 and $500{ }^{\circ} \mathrm{C}$. At temperature greater than $400{ }^{\circ} \mathrm{C}$, the interfacial reaction between $\mathrm{Ni}$ and $\mathrm{Ti}$ film and silicon substrate occurs leading to the diffusion of $\mathrm{Ni}$ species into the silicon to form $\mathrm{Ni}_{2} \mathrm{Si}$ at the interface (Wu et al 2001). The GIXRD pattern of Ni film annealed at $500{ }^{\circ} \mathrm{C}$ for 30 min show the clear evidence of $\mathrm{Ni}_{2} \mathrm{Si}$ phase formation along with the presence Ni cubic-phase. Thus it can be understood that the formation of metal-silicide is initiated at $500{ }^{\circ} \mathrm{C}$ without much consumption of $\mathrm{Ni}$ concentration at the film-substrate interface. The crystallite size was calculated from (1 111 ) peak by using wellknown Scherer's formula (1) and found to increase from 10 to $17 \mathrm{~nm}$ with the post-annealing temperature

$$
G=\frac{0 \cdot 9 \lambda}{\mathrm{FWHM} \cdot \cos \theta_{\mathrm{B}}} .
$$

GIXRD patterns for Ni films deposited at 300 and $500{ }^{\circ} \mathrm{C}$ substrate temperatures are shown in figure 4 . Even at high substrate temperature, the texturing of grains was favourable in the (1 111 ) direction in Ni films. However, GIXRD pattern for Ni films fail to show any evidence of nickel silicide formation at high substrate temperature near the film/substrate interface. The grain size was found to increase from 18 to $33 \mathrm{~nm}$ for Ni films as the 


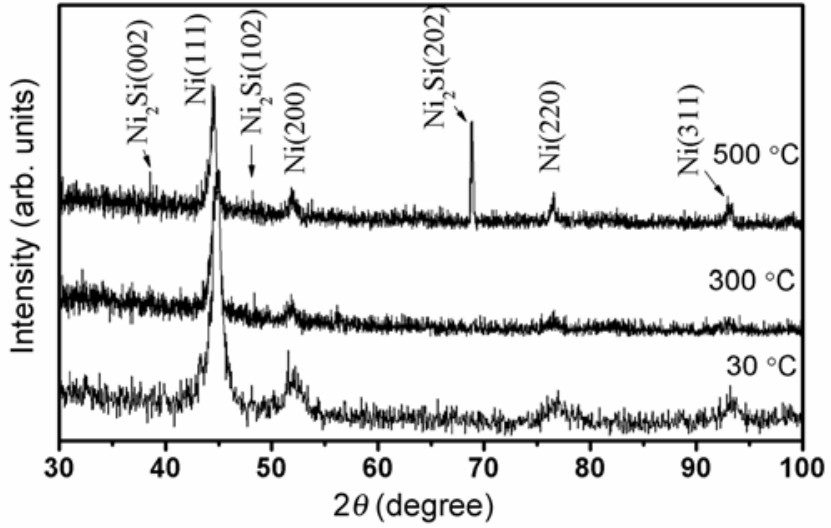

Figure 3. GIXRD plot for Ni films at different post-annealing temperatures.

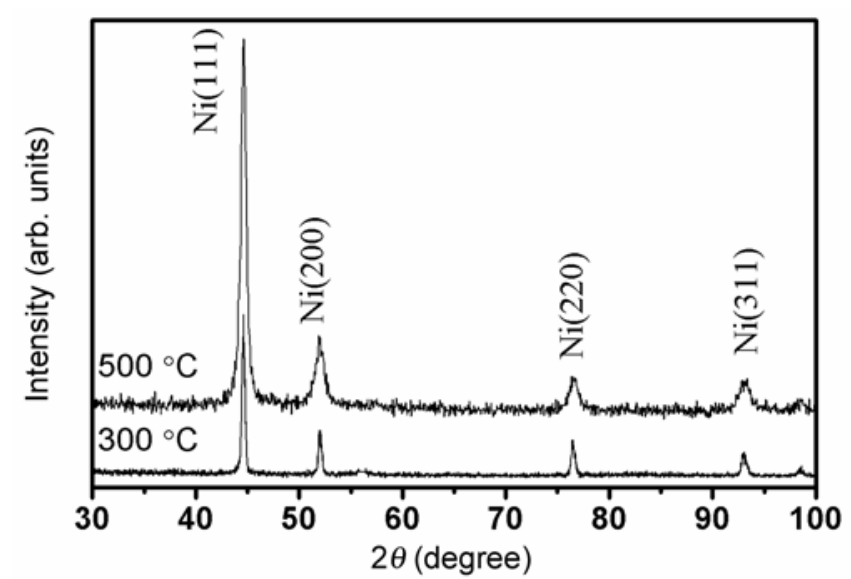

Figure 4. GIXRD plot for Ni films at different substrate temperatures.

deposition temperature was raised from 300 to $500{ }^{\circ} \mathrm{C}$. Similar observation has been reported (Chawla et al 2008) in case of Ti films, which suggest that increase in surface and grain boundary diffusivity of adatoms causes the grain growth at high substrate temperature leading to the increase in the grain size and the roughness of the films. This discussion seems to be relevant in the present case too.

\subsection{Atomic force microscopy analysis}

To investigate the effects of substrate temperature on the surface topography and roughness of $\mathrm{Ni}$ films, AFM analysis was carried out on Ni films. Figure 5(a)-(c) shows the AFM images of the $\mathrm{Ni}$ films deposited on $\mathrm{Si}$ substrates held at 30,300 and $500{ }^{\circ} \mathrm{C}$, respectively. As it is evident from the AFM images, the grain size increases with the increase in substrate temperature during deposition. The root mean square (rms) roughness values were calculated for Ni films. Room temperature deposited $\mathrm{Ni}$


Figure 5. AFM images of $\mathrm{Ni}$ films deposited at (a) room temperature (scan size: $2 \times 2 \mu \mathrm{m}$ ) (b) $300{ }^{\circ} \mathrm{C}$ and (c) $500{ }^{\circ} \mathrm{C}$ (scan size: $4 \times 4 \mu \mathrm{m}$ ).

film has an rms roughness value of $3.85 \mathrm{~nm}$. Further, rms roughness values were found to increase from 10 to $23 \mathrm{~nm}$ as the substrate temperature was increased from 300 to $500{ }^{\circ} \mathrm{C}$. The variation in surface topography with substrate temperature is the consequence of grain growth taking place due to the increase in rate of surface 

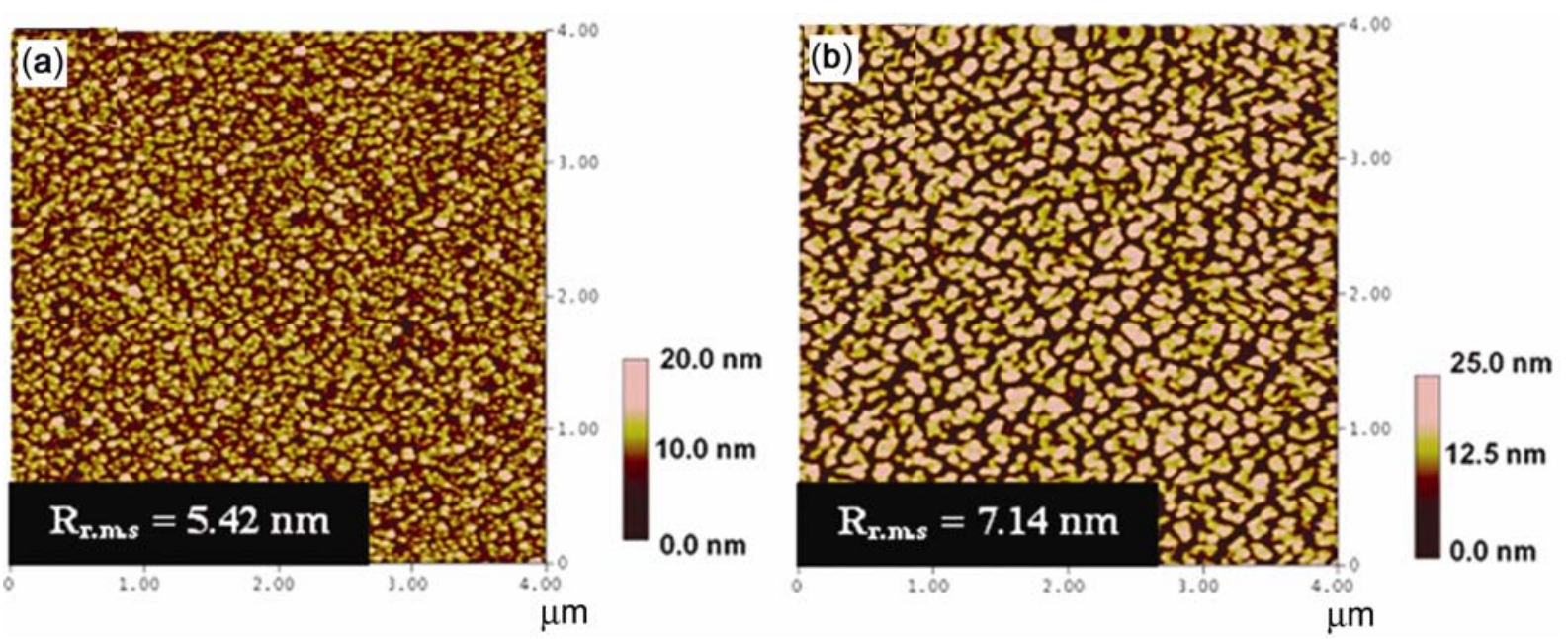

Figure 6. AFM images of $\mathrm{Ni}$ films deposited at room temperature followed by post-annealing at (a) $300{ }^{\circ} \mathrm{C}$ and (b) $500{ }^{\circ} \mathrm{C}$

migration of adatoms. When films are sputter deposited on substrate held at higher temperature, surface migration of the adatoms with higher energy takes place. This is due to the fact that the adatoms gain additional energy apart from the kinetic energy while they reach the growing film surface. This would result in the promotion of larger grains due to higher surface migration of adatoms. The increase in film roughness is probably due to the increase in the lateral $\mathrm{Ni}$ grain size. It should also be noted that the normal grain growth is not expected in thin films, since the microstructural evolution in such thin films is governed by the average grain size comparable with the film thickness and where the grain boundaries are perpendicular to the film surface and across its whole thickness (Di Nunzio 2003). Instead, abnormal grain growth takes place often leading to bimodal grain size distribution caused by secondary grain growth, in which case, some grains may grow excessively large relative to surrounding ones.

Figure 6(a) and (b) represents the AFM images of $\mathrm{Ni}$ films post-annealed at 300 and $500{ }^{\circ} \mathrm{C}$ for $30 \mathrm{~min}$ after deposition. From the topographical details of Ni films it is evident that the grain growth had taken place upon annealing treatment. The roughness was found to increase from 5.42 to $7 \cdot 14 \mathrm{~nm}$ as the annealing temperature was increased from 300 to $500{ }^{\circ} \mathrm{C}$. There is also a clear evidence of the presence of wide channels in between the grains suggesting the grain coalescence at high temperature.

\subsection{Field emission-scanning electron microscopy (FE-SEM) analysis}

Figure 7(a) and (c) shows the planar FE-SEM images of $\mathrm{Ni}$ films post-annealed at 300 and $500{ }^{\circ} \mathrm{C}$ for $30 \mathrm{~min}$. From the micrograph it is clear that there is negligible improvement in the microstructure for $\mathrm{Ni}$ films postannealed at $300{ }^{\circ} \mathrm{C}$. However, at annealing temperature of $500{ }^{\circ} \mathrm{C}$, the grain size was found to be $\sim 0.1 \mu \mathrm{m}$. The cross-sectional FE-SEM micrographs of the films annealed at 300 and $500{ }^{\circ} \mathrm{C}$ shown in figure 7(b) and (d) prove the coalescence of individual islands leading to columnar microstructure separated by grain boundaries. In addition, the channels appear to be wider with reduction in their number density.

As pointed out earlier, during room temperature deposition of Ni films, the lack of atomic mobility on the substrate surface restricts nucleation at most favourable sites (valleys) on the substrate This causes the film to grow vertically instead of laterally. An ideal growth leads to smooth-continuous film even when deposited at low substrate temperature provided deposition rate of the film is nearly equal to the film nucleation rate. However, in the present case, it is presumed that the rate at which adatoms deposit on the substrate (deposition rate) is lower than nucleation rate. Due to this, the deposited adatoms grow as individual islands resulting in less-denser film microstructure. This justifies the presence of wide channels in between the grains, even after coalescence of neighbouring grains, when the films are subjected to the postannealed Ni films at high temperature.

The crack-like microstructure which was previously observed in as-deposited Ni films was not observed in $\mathrm{Ni}$ films deposited on Si substrate held at 300 and $500{ }^{\circ} \mathrm{C}$ as shown in figure 8(a) and (c). At substrate temperatures of 300 and $500{ }^{\circ} \mathrm{C}$, the $T / T_{\mathrm{m}}$ ratio of Ni films was calculated to be 0.33 and 0.45 , respectively. These ratios lie in zone $T$ (transition zone) and zone II of Thornton's structure zone model (SZM) and the expected microstructure is large columnar structure with densely packed grain boundaries without channels in between the islands (Inoue et al 2009). Atomic mobility on the substrate 

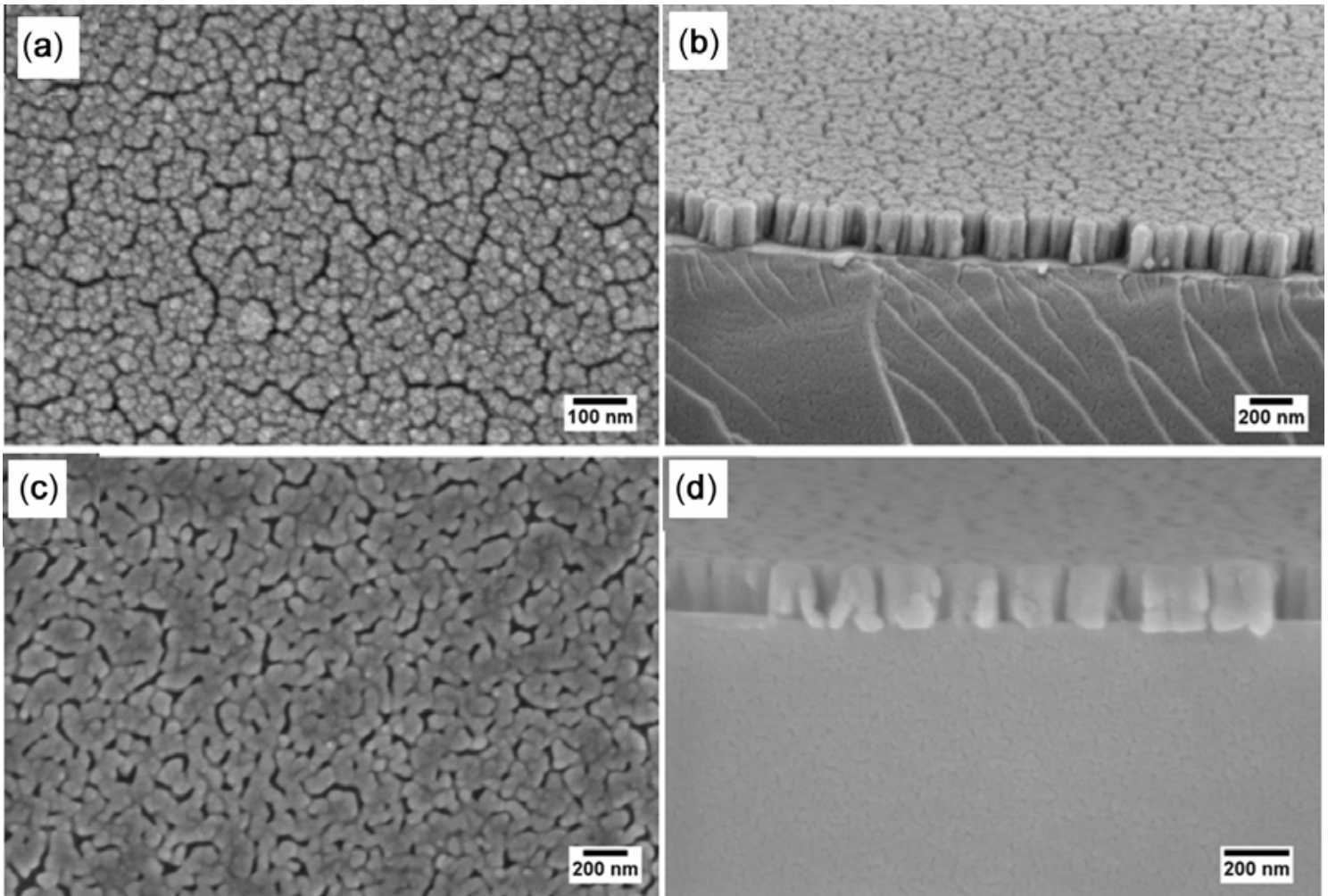

(d)

Figure 7. Planar and cross-sectional FE-SEM images of post-annealed Ni films: (a) and (b) $300{ }^{\circ} \mathrm{C}$, and (c) and (d) $500{ }^{\circ} \mathrm{C}$ for $30 \mathrm{~min}$.
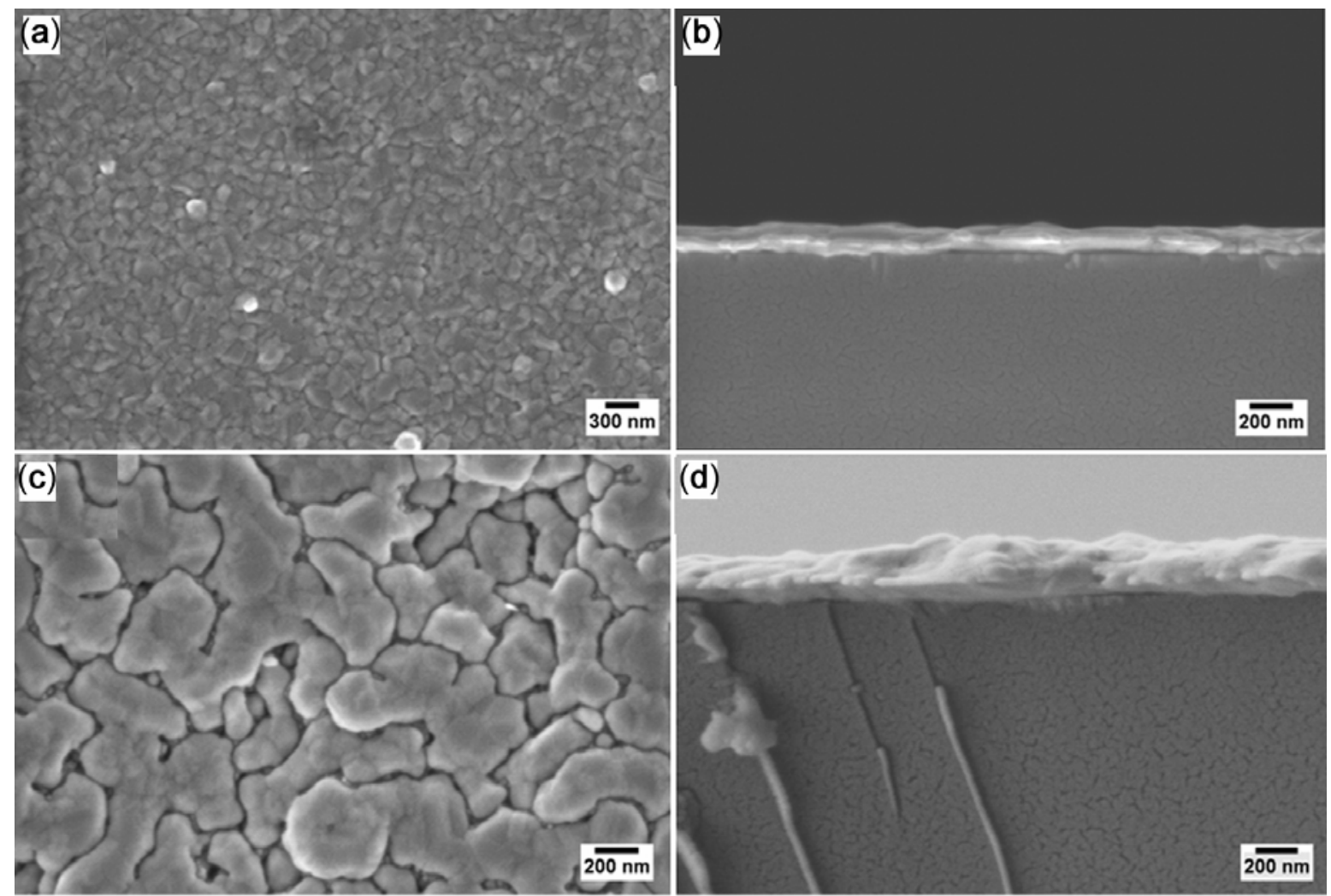

Figure 8. Planar and cross-sectional FE-SEM images of Ni films deposited at substrate temperature of (a) and (b) $300{ }^{\circ} \mathrm{C}$, and (c) and (d) $500{ }^{\circ} \mathrm{C}$. 
surface increases thereby adatom condensation occurs preferentially at the surface concavities leading to the smoother surface and denser-Ni film. Figure 8(b) and (d) shows the cross-sectional FE-SEM microstructure of $\mathrm{Ni}$ films deposited at substrate temperature 300 and $500{ }^{\circ} \mathrm{C}$. A near-equiaxed grain structure with densely packed microstructure comprising large lateral grain size was observed. This type of film microstructure shows the combination of layer-by-layer growth accompanied with island formation obeying Stranski-Krastanov growth model.

\subsection{Transmission electron microscopy analysis}

In order to investigate any silicide formations, crosssectional TEM studies were carried out on Ni film deposited at $500{ }^{\circ} \mathrm{C}$ substrate temperature. However, results did not reveal the formation of nickel silicides or any type of interfacial reaction between $\mathrm{Ni}$ and $\mathrm{Si}$ as shown in figure 9(a). The corresponding selected area electron diffraction pattern (SAED) contains low intensity rings which are indexed to $\mathrm{Ni}$ phase and the spots are indexed to Si substrate (figure 9b). At substrate temperature of $500{ }^{\circ} \mathrm{C}$, the metal supply is enormous with insignificant metal consumption due to the relative lowering of deposition temperature. In present case, the deposition rate of in situ heated $\mathrm{Ni}$ films $(13 \pm 3 \mathrm{~nm} / \mathrm{min})$ is higher than that deposition rate reported in literature; this might have delayed the formation of silicides at the interface. Similarly when compared to the electron beam evaporated $\mathrm{Ni}$ films, this value is high enough to restrict the interfacial reactions as reported (Julies et al 1999). The basic principles behind the formation of metal-silicide on Si substrates are: (i) solid state diffusion yielding sequential silicides formation; and (ii) deposition at extremely low rates on heated substrates allowing instantaneous reaction of film and substrate at the time of deposition itself.

The principle behind the latter process is to reduce the concentration of metal at the growth interface during compound phase formation by performing the deposition slowly while keeping the substrate at high temperature. Therefore, in the present case, deposition of Ni films on heated substrates at temperatures 300 and $500{ }^{\circ} \mathrm{C}$ has negligible effect on the nickel silicide phase formation. This shows that the formation of nickel silicide depends not only on the kinetic energy of the sputtered $\mathrm{Ni}$ atoms but also depend upon the morphology of the films based on diffusion temperature and time. However, formation of such products in small amount cannot be totally ruled out and further investigations are necessary to confirm the presence or absence of such silicides.

The formation of metal-silicides which were previously detected in GIXRD analysis (figure 3) for Ni film postannealed at temperature of $500{ }^{\circ} \mathrm{C}$ was thoroughly examined by TEM analysis as shown in figure 10(a) and (b). On closer observation, the presence of a homogeneous thin region growing adjacent to $\mathrm{Ni}$ and $\mathrm{Si}$ interface (represented by thick arrow) was evident and considered as a part of interfacial diffusion layer. The diffusion front at the interface appears to be a series of isosceles triangles with vertex $70^{\circ}$ and size of the triangles appears to be non-uniform as represented by dotted circle and triangle in figure 10(b). The formation of such diffusion region at the film-substrate interface is believed to set a pathway for the interdiffusion of $\mathrm{Ni}$ atoms through the silicide/Si interface resulting in faster growth of nickel silicides. Qiu (2003) observed similar formation of silicides in reactivesputter deposition of $\mathrm{Ni}$ films on $\mathrm{Si}$ at $200^{\circ} \mathrm{C}$ and accounted for the formation of isosceles triangle diffusion front as the diffusion of $\mathrm{Ni}$ atom along the $\left(\begin{array}{lll}1 & 1 & 1\end{array}\right)$ planes of Si substrate. Figure 10(c) represents the electron
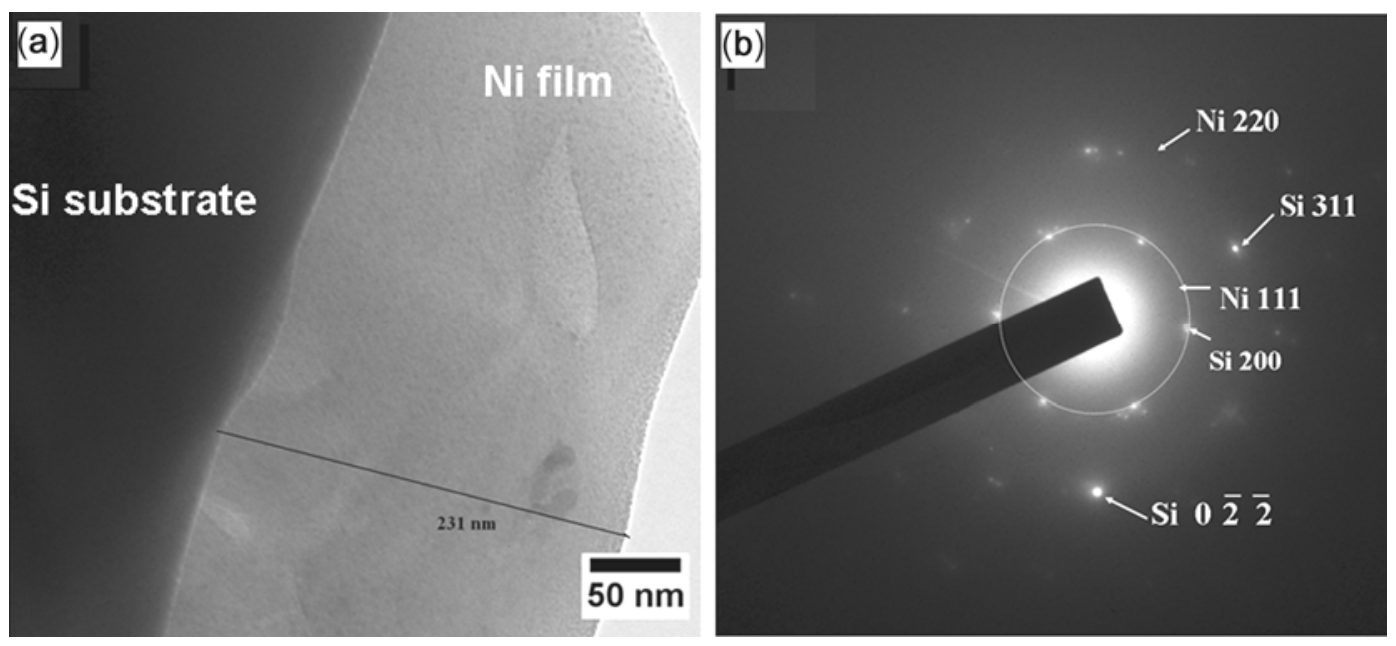

Figure 9. $\mathrm{Ni}$ film deposited on $\mathrm{Si}$ substrate at $500^{\circ} \mathrm{C}$ : (a) cross-sectional TEM micrograph and (b) corresponding SAED. 

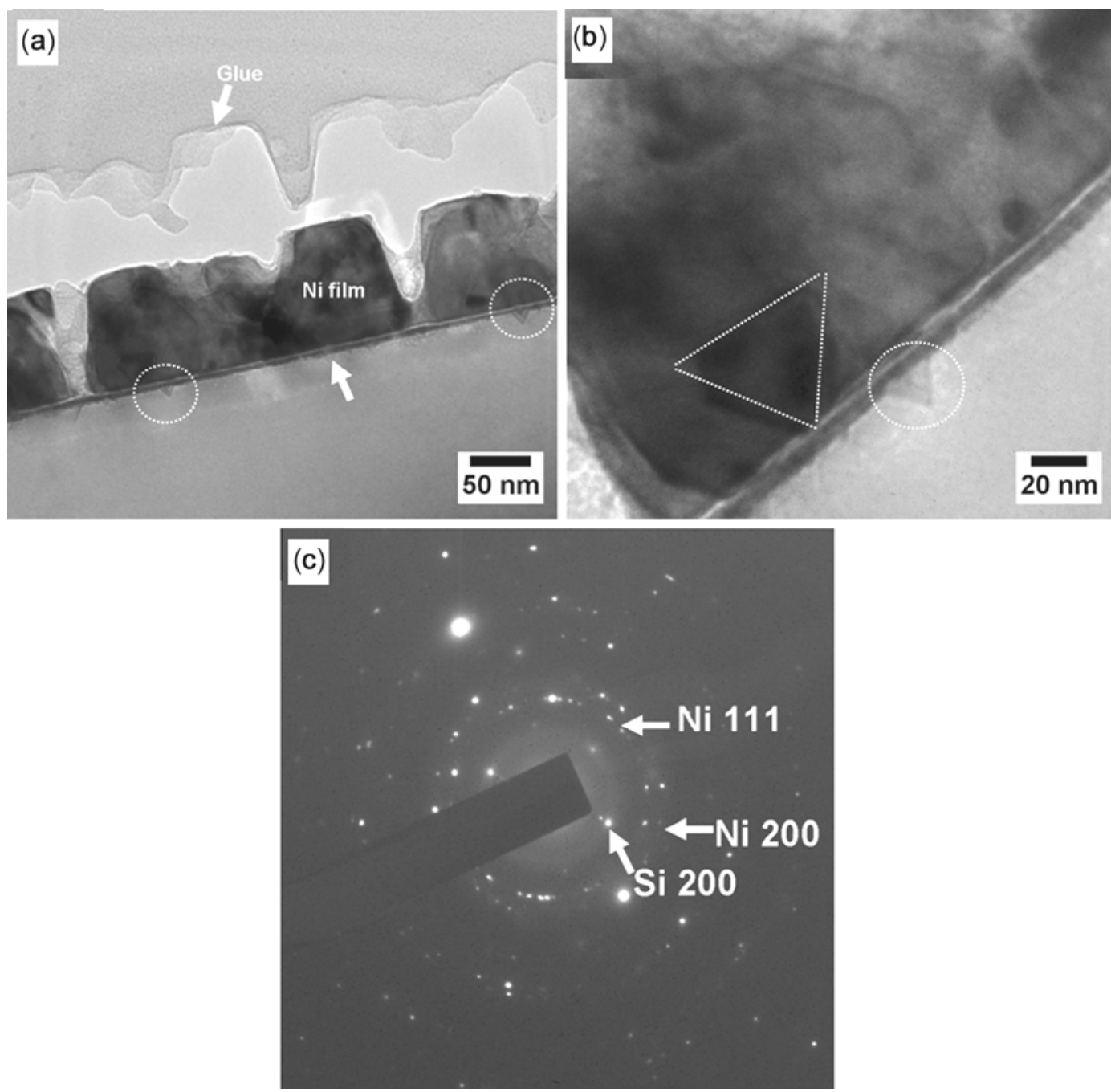

Figure 10. Post-annealed $\mathrm{Ni}$ films at $500{ }^{\circ} \mathrm{C}$ : (a) cross-sectional bright field transmission electron micrograph at $50 \mathrm{kV}$, (b) cross-sectional bright field transmission electron micrograph at $150 \mathrm{kV}$ and (c) corresponding SAED.

diffraction pattern taken close to the film-substrate interface area. The weak and diffused rings are indexed to $\mathrm{Ni}$ phase and the low intensity spots are indexed to Si substrates. The presence of faded or very diffused rings in electron diffraction pattern signifies that $\mathrm{Ni}$ is un-reacted which constitutes the major part of the film. On the other hand, some of the spots in the diffraction pattern could not be indexed as the diffraction spots from $\mathrm{Ni}_{2} \mathrm{Si}$.

This indicates that the interface is not pure $\mathrm{Ni}_{2} \mathrm{Si}$, but is a mixture of $\mathrm{Ni}, \mathrm{Si}$ and $\mathrm{Ni}_{2} \mathrm{Si}$. However, a few researchers have observed the formation of $\mathrm{Ni}_{2} \mathrm{Si}$ at low temperature $\left(200{ }^{\circ} \mathrm{C}\right)$ followed by subsequent high temperature annealing which leads to the conversion of $\mathrm{Ni}_{2} \mathrm{Si}$ into $\mathrm{NiSi}$ and $\mathrm{NiSi}_{2}$ phases (Kim and Cooley 1987; Vantomme et al 1999). In metal-silicon interaction, the formation of silicides is usually initiated at $200{ }^{\circ} \mathrm{C}$ at metal/Si interface. Metal being primary diffusing species diffuse into the $\mathrm{Si}$ substrate at low temperature forming $\mathrm{M}_{2} \mathrm{Si}$ as initial interfacial product. The diffusion front at the interface is formed by a series of isosceles triangles, which enables further diffusion of $\mathrm{Ni}$ atoms into the $\mathrm{Si}$ substrates. At temperature greater than $400^{\circ} \mathrm{C}$, the entire metal is converted to $\mathrm{M}_{2} \mathrm{Si}$ and further, the reaction proceeds to form mono-silicides. At temperatures greater than $600{ }^{\circ} \mathrm{C}$, di-silicides are formed by consuming all of the metal film. This particular case was observed for the electron beam evaporated films with metal film thickness of 10-50 nm (Julies et al 1999).

However, the scenario might be slightly different when considering higher film thickness. In addition, the fact that the Ni films of thickness of the order of $10-50 \mathrm{~nm}$ deposited using electron beam evaporation and, subsequently, subjected to rapid thermal annealing treatments, explains the delay in silicide formation at temperature around $500{ }^{\circ} \mathrm{C}$ in the present case where the sputtered deposited films are of $\sim 180 \mathrm{~nm}$ film thickness. Both 
GIXRD and cross-sectional TEM analysis in the present study revealed the formation of $\mathrm{Ni}_{2} \mathrm{Si}$ in the form of triangular diffusion fronts at the film-substrate interface for Ni films deposited on unheated substrate followed by solid-phase reaction. Therefore, this process might be beneficial especially while producing $\mathrm{Ni}-\mathrm{Ti}$ shape memory alloy films which have to undergo the process of crystallization at temperatures around $700{ }^{\circ} \mathrm{C}$ where the metal-interactions with $\mathrm{Si}$ are more dominant.

\section{Conclusions}

This study provides an understanding of the interactions between $\mathrm{Ni}$ and $\mathrm{Si}$ based on the growth morphology of $\mathrm{Ni}$ films at different substrate conditions. The work represented here is explicitly different from the previously reported work on nickel silicide formation in terms of thickness and growth morphology. Ni films deposited at room temperature revealed columnar morphology and tend to retain the morphology even at high post-annealing temperature. This columnar morphology of sputtered $\mathrm{Ni}$ films is believed to be the driving force for the silicide formation in the present case. On the contrary, Ni films deposited in situ at higher substrate temperature revealed smooth and continuous grain morphology which did not show any trace of silicide formation. Hence, it is concluded that columnar morphology is an additional factor apart from thickness, deposition rate and temperature which affect the interfacial reactions between $\mathrm{Ni}$ and $\mathrm{Si}$.

\section{Acknowledgements}

The authors are grateful to the Indian Institute of Technology, Kharagpur, for the financial support provided for this research.

\section{References}

Abdul-Letif A M 2007 Physica B: Condensed Matter 388107

Abhaya S, Amarendra G, Kalavathi S, Padma Gopalan, Kamruddin M, Tyagi A K, Sastry V S and Sundar C S 2007 Appl. Surf. Sci. 2533799

Chang C A 1986 J. Appl. Phys. 601220

Chawla V, Jayaganthan R, Chawla A K and Chandra R 2008 Mater. Chem. Phys. 111414
Chen J Z and Wu S K 2000 Thin Solid Films 339194

Chu J P, Lai Y W, Lin T N and Wang S F 2000 Mater. Sci. Eng. A277 11

D’Heurle F M, Peterson C S, Baglin J E E, La Placa S J and Wong C Y 1984 J. Appl. Phys. 124208

Di Nunzio P E 2003 Phys. Rev. B68 115432

Fu Y, Du H and Zhang S 2003 Thin Solid Films 44485

Fu Y, Du H, Huang W, Zhang S and Hu M 2004 Sens. Actuators A112 395

Fu Y, Du H, Zhang S and Ong S E 2005 Thin Solid Films 476 352

Inoue S, Sawada N and Namazu T 2009 Vacuum 83664

Ishida A, Sato M and Miyazaki S 1999 Mater. Sci. Eng. A273 754

Johnson A D 1991 J. Micromech. Microeng. 134

Julies B A, Knoesen D, Pretorius R and Adams D 1999 Thin Solid Films 347201

Kim N P and Cooley R F 1987 Thin Solid Films 153447

Kohl M 2004 Shape memory actuators: microtechnology and MEMS series (Berlin: Springer)

Krulevitch P, Ramsey P B, Makowiecki D M, Lee A P, Northrup M A and Johnson G C 1996 Thin Solid Films 274101

Martins R M S, Schell N, Mucklich A, Reuther H, Beckers M, Silva R J C, Pereira L and Braz Fernandes F M 2008 Appl. Phys. A91 291

Ohta A, Bhansali S, Kishimoto I and Umeda A 2000 Sens. Actuators 86165

Poate J M, Tu K N and Mayer J W 1978 Thin films interdiffusion and reactions (Canada: Wiley-Interscience Publications)

Qiu H, Tian Y and Hashimoto M 2003 Vacuum 70493

Sanjabi S, Cao Y Z, Sadrnezhaad S K and Barber Z H 2005 J. Vac. Sci. Technol. A23 1425

Shih C L, Lai B K, Kahn H, Philips S M and Heurer A H 2001 J. Micromech. Syst. 1069

Stemmer S, Duscher G, Scheu S, Heuer A H and Ruhle M 1997 J. Mater. Res. 121734

Surbled P, Clerc C, Le Pioufle B, Ataka M and Fujita H 2001 Thin Solid Films $\mathbf{4 0 1} 52$

Takabayashi S, Tanino K and Kitagawa K 1997 Mater. Sci. Res. Int. 3220

Vantomme A, Degroote S, Dekoster J, Langouche G and Pretorius R 1999 Appl. Phys. Lett. 743137

Walker J A, Gabriel K J and Mehregany M 1990 Sens. Actuators A21-23 243

Wolf R H and Heuer A H 1995 J. Micromech. Syst. 4206

Wu S K, Chen J Z, Wu Y J, Wang J Y, Yu M N, Chen F R and Kai J J 2001 Philos. Mag. A81 1939

Wu S K, Su J J and Wang J Y 2004 Philos. Mag. A84 1209 